\title{
FAKTOR-FAKTOR YANG MEMPENGARUHI KECEMASAN MAHASISWA DALAM MENYELESAIKAN TUGAS AKHIR DI STIKES PAYUNG NEGERI PEKANBARU
}

\author{
Eka Malfasari ${ }^{1}$, Yeni Devita ${ }^{2}$, Fitry Erlin ${ }^{3}$, Filer $^{4}$ \\ ${ }_{1,2,3,4}$ Program Studi Ilmu Keperawatan Stikes Payung Negeri Pekanbaru \\ Jl Tamtama No 06 Labuh Baru Pekanbaru Riau 28291 \\ mizzeka18@gmail.com
}

\begin{abstract}
Abstrak
Kesulitan mahasiswa menyelesaikan tugas akhir sering menjadi beban bagi mahasiswa itu sendiri dan menjadikan beban tersebut sebagai pikiran negatif yang nantinya akan menimbulkan kecemasan. Tujuan penelitian ini adalah untuk melihat faktor-faktor yang mempengaruhi kecemasan mahasiswa yang sedang menyelesaikan tugas akhirnya. Penelitian ini adalah penelitian kuantitafif kolerasi dengan pendekatan cross sectional. Penelitian ini melibatkan seluruh mahasiswa STIkes Payung Negeri Pekanbaru dari berbagai jurusan dengan jumlah populasi 272 mahasiswa yang sedang menyelesaikan tugas akhir dengan 162 sampel. Alat ukur faktor dosen pembimbing, teman sebaya dan lingkungan menggunakan kuesioner yang dimodifikasi oleh peneliti dan dilakukan uji validitas dan reabilitas, sedangkan alat ukut kecemasan menggunakan State and Trait Anxiety Inventory (STAI) yang terdiri dari 20 pertanyaan. Penelitian ini dianalisis menggunakan komputer dengan uji chi square. Hasil penelitian menunjukkan bahwa terdapat hubungan yang signifikan antara dosen pembimbing, teman sebaya dan lingkungan dengan ansietas mahasiswa yang sedang menyelesaikan tugas akhir dengan $p$ value $<0,05$. Penelitian ini merekomendasikan kepada peneliti selanjutnya untuk upaya yang bisa dilakukan untuk mengatasi kecemasan mahasiswa saat menyelesaikan tugas akhir.
\end{abstract}

Kata Kunci : Ansietas,Mahasiswa,Tugas Akhir

\begin{abstract}
The difficulties when preparing the thesis by students often perceived as a heavy burden, consequently the perceived difficulties develop into a negative attitude that can eventually cause anxiety. The purpose of this study is to determine the factors affecting students' anxiety to preparing the thesis at STIKes Payung Negeri Pekanbaru. This study is a correlation quantitative study with cross sectional approach. The population in this study is 272 students and using stratified random sampling to 162 samples in STIKes Payung Negeri Pekanbaru. Lectures, peers and environtmenr measured using questionners made by researcher, and anxiety measured by State and Trait Anxiety Inventory (STAI). The analysis used frequency distribution and Chi Square test. The results of this study are, the are significant relationship between lecturers ( $p$ value $=0,001)$, peers ( $p$ value $=0,000)$, environment $(p$ value $=0,018)$, with anxiety with all $p$ value $<0.05$. The next researcher must find how to reduce student anxiety to face their thesis.
\end{abstract}

Keywords : Student,Anxiety, Thesis

\section{PENDAHULUAN}

Tugas akhir merupakan salah satu syarat utama bagi seorang mahasiswa untuk memperoleh gelar kelulusan, dimana tidak semua mahasiswa punya kesiapan saat menghadapi tugas akhir tersebut. Fase ini biasanya menjadi stresor tersendiri di kalangan mahasiswa. Ini terjadi bukan hanya karena banyak anggapan bahwa penyusunan tugas akhir itu sulit tetapi juga karena proses dalam penyusunan tugas akhir yang panjang. Anggapan yang demikian menyebabkan beberapa mahasiswa menjadi cemas ketika 
Eka Malfasari ${ }^{1}$, Yeni Devita ${ }^{2}$, Fitry Erlin $^{3}$, Filer $^{4}$,Faktor-Faktor Yang Mempengaruhi Kecemasan Mahasiswa Dalam Menyelesaikan Tugas Akhir Di Stikes Payung Negeri Pekanbaru

harus menghadapi tugas akhir (Mukhayyaroh, 2012).

Kecemasan dapat muncul sebagai suatu respon fisiologis untuk mengantisipasi suatu permasalahan yang mungkin akan datang atau muncul sebagai gangguan jika timbul berlebihan (Prabowo, 2010). Sampai saat ini, perasaan cemas masih merupakan penyakit masyarakat. Umumnya, perasaan cemas dan rasa gelisah adalah gejala penyakit jiwa atau gangguan mental belaka, tapi perasaan cemas yang berlebihan dapat pula menyerang organ tubuh kita (Batara, 2010).

Berdasarkan data yang diperoleh di STIKes Payung Negeri Pekanbaru pada tahun 2016 jumlah mahasiswa tingkat akhir yang akan menyelesaikan tugas akhir adalah sebanyak 272 Orang dengan jumlah dari masing-masing prodi sebagai berikut : pada Prodi DIII Kebidanan 80 orang, DIII Keperawatan 37 orang, SI Keperawatan program 123 orang, dan S1 Kesehatan Masyarakat 32 orang. Hasil studi pendahuluan yang dilakukan oleh penulis pada 35 orang, 28 orang $(80 \%)$ diantaranya mengatakan merasa takut dan cemas disertai perasaan stres dalam menyusun tugas akhir, sedangkan 7 orang (20\%) mengatakan tidak terlalu memikirkan kesulitan dalam menyusun tugas akhir. Untuk itu peneliti ingin melihat faktor-faktor yang mempengaruhi kecemasan mahasiswa yang sedang menyelesaikan tugas akhir.

\section{METODE PENELITIAN}

Penelitian ini merupakan penelitian kuantitatif dengan rancangan detugas akhir korelasi dengan pendekatan "cross sectional". Penelitian ini dilakukan di STIKes Payung Negeri Pekanbaru. Populasi dalam penelitian ini berjumlah 272 orang, sedangkan sampel penelitian berjumlah 162 orang dan akan di ambil dengan metode stratified random sampling. Alat ukur faktor dosen pembimbing, teman sebaya dan lingkungan menggunakan kuesioner yang dimodifikasi oleh peneliti dan dilakukan uji validitas dan reabilitas, sedangkan alat ukut kecemasan menggunakan State and Trait Anxiety Inventory (STAI) yang terdiri dari 20 pertanyaan. Data di analisis menggunakan uji chi square dan di olah menggunakan komputer.

\section{HASIL PENELITIAN}

Berikut merupakan hasil penelitian faktor-faktor yang mempengaruhi kecemasan mahasiswa yang sedang menyelesaikan tugas akhir.

Tabel 1

\section{Karakteristik Mahasiswa yang Sedang} Menyelesaikan Tugas Akhir

\begin{tabular}{|c|c|c|c|c|}
\hline No & Variabel & Kategori & $\begin{array}{l}\text { Frekuensi } \\
\text { (n) }\end{array}$ & $\begin{array}{l}\text { Present } \\
\text { ase } \\
(\%)\end{array}$ \\
\hline \multirow[t]{5}{*}{1} & \multirow[t]{5}{*}{ Usia } & 20 & 25 & 15,4 \\
\hline & & 21 & 58 & 35,8 \\
\hline & & 22 & 57 & 35,2 \\
\hline & & 23 & 21 & 13,0 \\
\hline & & 24 & 1 & 6 \\
\hline \multirow[t]{3}{*}{2} & \multirow[t]{3}{*}{ Jenis Keamin } & Laki-laki & 35 & 21,6 \\
\hline & & Perempuan & 127 & 78,4 \\
\hline & & PSIK & 73 & 45,1 \\
\hline
\end{tabular}


Jurnal Ners Indonesia, Vol. 8, No. 2, Maret 2018

\begin{tabular}{lllll}
\hline 3 & Program Studi & IKM & 19 & 11,7 \\
\cline { 3 - 5 } & & DIII Perawat & 22 & 13,6 \\
\cline { 3 - 5 } & & DIII Bidan & 48 & 29,6 \\
\hline \multirow{2}{*}{4} & \multirow{2}{*}{ Kecemasan } & Ringan & 35 & 21,6 \\
\cline { 3 - 5 } & & Sedang & 121 & 74,7 \\
\cline { 3 - 5 } & & Berat & 6 & 3,7 \\
\hline \multirow{2}{*}{5} & Pengaruh & Rendah & 69 & 42,6 \\
\cline { 3 - 5 } & Teman Sebaya & Tinggi & 93 & 57,4 \\
\hline 6 & Lingkungan & Baik & 56 & 34,6 \\
\cline { 3 - 5 } & & Buruk & 106 & 65,4 \\
\hline 7 & Dosen & Rendah & 73 & 45,2 \\
\cline { 3 - 5 } & Pembimbing & Tinggi & 89 & 54,9 \\
\hline
\end{tabular}

Sumber : Data Primer 2017

Berdasarkan tabel 4.1 didapatkan data bahwa mayoritas responden berusia2 1 tahun yaitu sebanyak 58 responden $(35,8 \%)$. Mayoritas responden berjenis kelamin perempuan yaitu sebanyak 127 responden dengan persentase $(78,4 \%)$ dan berasal dari berasal dari
Program Studi Ilmu Keperawatan STIKes Payung Negeri Pekanbaru yaitu sebanyak 73 responden dengan persentase $(45,1 \%)$.

Selain itu dapat dilihat di tabel 1 bahwa mayoritas 121 responden dengan kecemasan sedang persentase $(74,7 \%)$. Serta memiliki mayoritas 93 responden dengan persentase $(57,4 \%)$ memiliki dukungan dari teman sebaya yang tinggi. Kemudian Pengaruh lingkungan yang baik $(65,4 \%)$ merupakan mayoritas dan mayoritas 89 responden dengan persentase $(54,9 \%)$ memiliki pengaruh dosen pembimbing tinggi.

Tabel 2

Hubungan Dosen Pembimbing dengan Kecemasan Mahasiswa saat menyelesaikan Tugas Akhir

\begin{tabular}{|c|c|c|c|c|c|c|c|c|c|}
\hline \multirow{3}{*}{ Dosen Pembimbing } & \multicolumn{6}{|c|}{ Kecemasan } & \multirow{2}{*}{\multicolumn{2}{|c|}{ Total }} & \multirow{3}{*}{$P$ value } \\
\hline & \multicolumn{2}{|c|}{ Ringan } & \multicolumn{2}{|c|}{ Sedang } & \multicolumn{2}{|r|}{ Berat } & & & \\
\hline & $\mathrm{N}$ & $\%$ & $\mathrm{~N}$ & $\%$ & $\mathrm{~N}$ & $\%$ & $\mathrm{~N}$ & $\%$ & \\
\hline Rendah & 9 & 12,3 & 59 & 80,8 & 5 & 6,8 & 85 & 100 & \\
\hline Tinggi & 26 & 29,2 & 62 & 69,7 & 1 & 1,1 & 77 & 100 & 0,00 \\
\hline Jumlah & 35 & 21,6 & 121 & 74,7 & 6 & 3,7 & 162 & 100 & \\
\hline
\end{tabular}

Sumber : Data Primer 2017

Hasil analisis tabel 4.10 dapat dilihat bahwa responden dengan tingkat kecemasan sedang dan pengaruh dosen pembimbing tinggi sebanyak 62 orang $(69,7 \%)$, sedangkan responden dengan tingkat kecemasan sedang dan pengaruh dosen pembimbing rendah sebanyak59 orang (80,8 \%). Hasil uji statistik chi square diperoleh nilai $p$ $=0,009$ dan nilai signifikansi lebih kecil dari $5 \%(p=0,001<0,05)$ maka Ho di tolak, sehingga dapat disimpulkan ada hubungan kecemasan dengan dosen pembimbing di STIKes Payung Negeri Pekanbaru.
Tabel 3

Hubungan Dosen Pembimbing dengan Kecemasan Mahasiswa saat menyelesaikan Tugas Akhir

\begin{tabular}{|c|c|c|c|c|c|c|c|c|c|}
\hline \multirow{3}{*}{$\begin{array}{l}\text { Teman } \\
\text { sebaya }\end{array}$} & \multicolumn{6}{|c|}{ Kecemasan } & \multirow{2}{*}{\multicolumn{2}{|c|}{ Total }} & \multirow{3}{*}{$\begin{array}{c}P \\
\text { value }\end{array}$} \\
\hline & \multicolumn{2}{|c|}{ Ringan } & \multicolumn{2}{|c|}{ Sedang } & \multicolumn{2}{|c|}{ Berat } & & & \\
\hline & $\mathrm{N}$ & $\%$ & $\mathrm{~N}$ & $\%$ & $\mathrm{~N}$ & $\%$ & $\mathrm{~N}$ & $\%$ & \\
\hline Rendah & 5 & 7,2 & 59 & 85,5 & 5 & 7,2 & 69 & 100 & \multirow{3}{*}{0.000} \\
\hline Tinggi & 30 & 32,3 & 62 & 66,7 & 1 & 1,1 & 93 & 100 & \\
\hline Jumlah & 35 & 21,6 & 121 & 74,7 & 6 & 3,7 & 162 & 100 & \\
\hline
\end{tabular}

Sumber : Data Primer 2017

Hasil analisis tabel 4.12 dapat dilihat bahwa responden dengan tingkat kecemasan sedang dan pengaruh teman sebaya tinggi sebanyak 62 orang $(66,7 \%)$, sedangkan responden dengan tingkat kecemasan sedang 
Eka Malfasari ${ }^{1}$, Yeni Devita ${ }^{2}$, Fitry Erlin $^{3}$, Filer $^{4}$,Faktor-Faktor Yang Mempengaruhi Kecemasan Mahasiswa Dalam Menyelesaikan Tugas Akhir Di Stikes Payung Negeri Pekanbaru

dan pengaruh teman sebaya rendah sebanyak 59 orang $(85,5 \%)$. Hasil uji statistik chi square diperoleh nilai $p=0,000$ dan nilai signifikansi lebih kecil dari 5\% $(p=0,000<$
0,05) maka Ho di tolak, sehingga dapat disimpulkan ada hubungan kecemasan dengan teman sebaya di STIKes Payung Negeri Pekanbaru.

Tabel 4

Hubungan lingkungan dengan Kecemasan Mahasiswa saat menyelesaikan Tugas Akhir

\begin{tabular}{|c|c|c|c|c|c|c|c|c|c|}
\hline \multirow{3}{*}{ Lingkungan } & \multicolumn{6}{|c|}{ Kecemasan } & \multirow{2}{*}{\multicolumn{2}{|c|}{ Total }} & \multirow{3}{*}{$P$ value } \\
\hline & \multicolumn{2}{|c|}{ Ringan } & \multicolumn{2}{|c|}{ Sedang } & \multicolumn{2}{|c|}{ Berat } & & & \\
\hline & $\mathrm{N}$ & $\%$ & $\mathrm{~N}$ & $\%$ & $\mathrm{~N}$ & $\%$ & $\mathrm{~N}$ & $\%$ & \\
\hline Baik & 6 & 10,7 & 46 & 82,1 & 4 & 7,1 & 60 & 100 & \\
\hline Buruk & 29 & 27,4 & 75 & 70,8 & 2 & 1,9 & 102 & 100 & 0,018 \\
\hline Jumlah & 35 & 21,6 & 121 & 74,7 & 6 & 3,7 & 162 & 100 & \\
\hline
\end{tabular}

Sumber : Data Primer 2017

Hasil analisis tabel 4.14 dapat dilihat bahwa responden dengan tingkat kecemasan sedang dan pengaruh lingkungan baik sebanyak 75 orang $(70,8 \%)$, sedangkan responden dengan tingkat kecemasan sedang dan pengaruh lingkungan buruk sebanyak 46 orang $(82,1 \%)$. Hasil uji statistik chi square diperoleh nilai $p=0,018$ dan nilai signifikansi lebih kecil dari 5\% ( $p=0,018<0,05)$ maka Ho di tolak, sehingga dapat disimpulkan ada hubungan kecemasan dengan lingkungan di STIKes Payung Negeri Pekanbaru

\section{PEMBAHASAN}

Hasil penelitian ini menyebutkan bahwa mayoritas respondn ada di usia 21 tahun, Menurut Haynes dalam Demak \& Suherman (2016) menyatakan bahwa usia muda lebih muda terkena tekanan (stres) psikologis dan cemas, karena kesiapan mental dan jiwa yang belum matang serta kurangnya pengalaman. Dalam penelitian ini kecemasan yang paling tinggi berada pada umur 21 sampai 23, hal ini sesuai dengan teori gangguan kecemasan bahwa kecemasan lebih sering dialami pada usia 21- 45 tahun. Menurut asumsi peneliti usia remaja cenderung mengalami kecemasan karena secara psikologis masih belum matang, apalagi jika mengenai tugas akhir yang baru pertama kali dihadapi oleh remaja, tentu hal ini akan menimbulkan bagi remaja. Remaja takut apakah bisa melalui nya atau tidak.

Responden penelitian ini mayoritas berjenis kelamin perempuan yaitu sebanyak 127 responden dengan persentase (78,4\%). Menurut Hawari (2008), wanita lebih mudah mengalami kecemasan dibandingkan dengan pria karena karena akibat dari reaksi saraf otonom yang berlebihan dengan naiknya sistem simpatis, naiknya norepinefrin, terjadi peningkatan pelepasan katekolamin, dan adanya gangguan regulasi serotonergik yang abnormal (Kaplan dan Sadock, 2008). 
Perempuan akan lebih mudah cemas dikarenakan ketidakmampuannya dibandingkan dengan laki-laki. Laki-laki lebih aktif dan eksploratif, sedangkan perempuan lebih sensitive sehingga perempuan lebih peka terhadap respon cemas yang terjadi (Nadia, 2008). Menurut asumsi peneliti wanita lebih mudah cemas daripada laki-laki karena wanita lebih emosional sedangkan laki- laki cenderung memandang suatu masalah dengan rasional dan lebih tenang.

Hasil analisis chi square dapat dilihat bahwa responden dengan tingkat kecemasan ringan dan pengaruh dosen pembimbing tinggi sebanyak 26 orang $(33,8 \%)$, sedangkan responden dengan tingkat kecemasan berat dan pengaruh dosen pembimbing rendah sebanyak 5 orang $(5,9 \%)$. Hasil uji statistik chi square diperoleh nilai $p=0,001$ dan nilai signifikansi lebih kecil dari 5\% $(p=0,001<$ 0,05) maka Ho di tolak, sehingga dapat disimpulkan ada hubungan kecemasan dengan dosen pembimbing di STIKes Payung Negeri Pekanbaru. Hasil penelitian ini sesuai dengan pendapat yang dikemukakan oleh Irham, dan Wiyani, (2014) yang menyebutkan bahwa faktor-faktor yang dapat menyebabkan kesulitan belajar pada siswa antara lain adalah guru, kualitas pembelajaran, instrumen, dan fasilitas pembelajaran. Dalam Penyelesaian Tugas Akhir Tugas akhir keempat hal tersebut tercermin dalam Kualitas Bimbingan Tugas akhir. Hasil penelitian ini juga diperkuat oleh penelitian yang dilakukan oleh Kusnendar, Suwachid and Wijayanto (2013) yang menunjukkan bahwa bimbingan tugas akhir memiliki pengaruh terhadap penyelesaian tugas akhir tugas akhir. Semakin aktif peran dosen pembimbing maka semakin rendah tingkat kecemasan mahasiswa dalam menghadap tugas akhir tugas akhir, sebaliknya apabila peran dosen tida aktif maka semakin tinggi tingkat kecemasan mahasiswa dalam menghadapi tugas akhir tugas akhir. Hubungan antara peran dosen pembimbing dengan tingkat kecemasan mahasiswa keperawatan dalam menghadapi tugas akhir tugas akhir memiliki kekuatan korelasi sedang. Kualitas Hasil penelitian menunjukkan bahwa responden dengan tingkat kecemasan ringan dan pengaruh teman sebaya tinggi sebanyak 30 orang $(32,3 \%)$, sedangkan responden dengan tingkat kecemasan berat dan pengaruh teman sebaya rendah sebanyak 5 orang (7,2\%). Hasil uji statistik chi square diperoleh nilai $p=0,000$ dan nilai signifikansi lebih kecil dari 5\% ( $p=0,000$ $<0,05)$ maka Ho di tolak, sehingga dapat disimpulkan ada hubungan kecemasan dengan teman sebaya di STIKes Payung Negeri Pekanbaru.

Hasil penelitian ini sesuai dengan pendapat yang dikemukakan oleh Irham dan Wiyani (2014) yang menyebutkan bahwa faktor-faktor yang dapat menyebabkan kesulitan belajar pada siswa antara lain adalah lingkungan sosial dan alam. Contoh yang termasuk dalam lingkungan sosial adalah teman sebaya. Hasil penelitian ini juga diperkuat oleh penelitian yang dilakukan oleh 
Eka Malfasari ${ }^{1}$, Yeni Devita ${ }^{2}$, Fitry Erlin $^{3}$, Filer $^{4}$,Faktor-Faktor Yang Mempengaruhi Kecemasan Mahasiswa Dalam Menyelesaikan Tugas Akhir Di Stikes Payung Negeri Pekanbaru

Kusnendar, Suwachid danWijayanto (2013) yang menunjukkan bahwa salah satu faktor yang mempengaruhi penyelesaian studi mahasiswa adalah teman bergaul. Semakin baik lingkungan teman sebaya yang dimiliki oleh mahasiswa yang sedang menempuh tugas akhir maka akan semakin baik pula proses penyelesaian tugas akhir tugas akhirnya karena lingkungan baik akan membawa dampak positif dalam proses belajar. Sebaliknya semakin buruk lingkungan teman sebaya yang dimiliki misalnya lingkungan teman sebaya yang suka menghabiskan waktu belajar maka akan semakin buruk pula penyelesaian tugas akhir tugas akhirnya. Hal ini menunjukkan bahwa lingkungan teman sebaya memiliki pengaruh positif terhadap penyelesaian tugas akhir tugas akhir (Hartato, 2016). Menurut asumsi peneliti teman sebaya sangat berpengaruh pada kecemasan mahasiswa, karena teman sebaya merupakan orang yang terdekat dengan mahasiswa. Jika teman sebaya mahasiswa sering memberikan motivasi dalam menyususn tugas akhir dan sering mengajak untuk mengerjakan tugas akhir bersama-sama maka akan mengurangi kecemasan yang dialami oleh mahasiswa Bimbingan Tugas akhir adalah tingkat atau kadar baik buruknya proses pemberian bantuan oleh dosen pembimbing kepada mahasiswa agar terhindar dari kesulitan belajar yaitu dalam rangka Penyelesaian Tugas Akhir Tugas akhir. Oleh karena itu, dapat kita pahami bahwa Kualitas Bimbingan Tugas akhir memiliki pengaruh positif terhadap Penyelesaian Tugas Akhir Tugas akhir dimana semakin baik Kualitas Bimbingan Tugas akhir maka akan semakin baik pula Penyelesaian Tugas Akhir Tugas akhir begitu juga sebaliknya semakin buruk Kualitas Bimbingan Tugas akhir maka akan semakin buruk juga proses Penyelesaian Tugas Akhir Tugas akhir yang sedang ditempuh mahasiswa yang bersangkutan (Hartato, 2016). Menurut asumsi peneliti dukungan dari dosen pembimbing berpengaruh pada kecemasan mahasiswa dalam menyusun tugas akhir, karena dosen pembimbing merupakan tempat mahasiswa bertanya dan mengungkapkan kesulitankesulitan yang di temukan mahasiswa selama penelitian. Jika dosen pembimbing sulit ditemui dan tidak bisa memberikan bimbingan secara maksimal pada mahasiswa bimbingannya maka akan menimbulkan kecemasan pada mahasiswa tersebut.

Sedangkan adanya hubungan dengan teman sebaya pada penelitian ini berhubungan positif dengan adanya kecemasan mahasiswa. Hasil penelitian menunjukkan bahwa responden dengan tingkat kecemasan ringan dan pengaruh teman sebaya tinggi sebanyak 30 orang $(32,3 \%)$, sedangkan responden dengan tingkat kecemasan berat dan pengaruh teman sebaya rendah sebanyak 5 orang (7,2\%). Hasil uji statistik chi square diperoleh nilai $p=0,000$ dan nilai 
Jurnal Ners Indonesia, Vol. 8, No. 2, Maret 2018

signifikansi lebih kecil dari 5\% ( $p=$ $0,000<0,05)$ maka Ho di tolak, sehingga dapat disimpulkan ada hubungan kecemasan dengan teman sebaya di STIKes Payung Negeri Pekanbaru. Hasil penelitian ini sesuai dengan pendapat yang dikemukakan oleh Irham dan Wiyani (2014) yang menyebutkan bahwa faktor-faktor yang dapat menyebabkan kesulitan belajar pada siswa antara lain adalah lingkungan sosial dan alam. Contoh yang termasuk dalam lingkungan sosial adalah teman sebaya. Hasil penelitian ini juga diperkuat oleh penelitian yang dilakukan oleh Kusnendar, Suwachid and Wijayanto (2013) yang menunjukkan bahwa salah satu faktor yang mempengaruhi penyelesaian studi mahasiswa adalah teman bergaul. Semakin baik lingkungan teman sebaya yang dimiliki oleh mahasiswa yang sedang menempuh tugas akhir maka akan semakin baik pula proses penyelesaian tugas akhir tugas akhirnya karena lingkungan baik akan membawa dampak positif dalam proses belajar. Sebaliknya semakin buruk lingkungan teman sebaya yang dimiliki misalnya lingkungan teman sebaya yang suka menghabiskan waktu belajar maka akan semakin buruk pula penyelesaian tugas akhir tugas akhirnya. Hal ini menunjukkan bahwa lingkungan teman sebaya memiliki pengaruh positif terhadap penyelesaian tugas akhir tugas akhir (Hartato, 2016).

Menurut asumsi peneliti teman sebaya sangat berpengaruh pada kecemasan mahasiswa, karena teman sebaya merupakan orang yang terdekat dengan mahasiswa. Jika teman sebaya mahasiswa sering memberikan motivasi dalam menyususn tugas akhir dan sering mengajak untuk mengerjakan tugas akhir bersama-sama maka akan mengurangi kecemasan yang dialami oleh mahasiswa.

Sedangkan faktor terakhir yaitu lingkungan juga mempengaruhi kecemasan mahasiswa saat menghadapi tugas akhir. Hasil penelitian ini juga diperkuat oleh penelitian yang dilakukan oleh Alafgani (2013) yang menunjukkan faktor yang mempengaruhi penyelesaian studi mahasiwa salah satunya adalah minimnya bahan dan ketersediaan buku di perpustakaan. Namun, menurut asumsi peneliti bahwa ketercapaian bahan tersebut saat ini bisa di akses secara online. Sehingga faktor lingkungan yang mempengaruhi adalah kurang memadainya fasilitas pelengkap seperti laptop dan printer.

\section{SIMPULAN}

Hasil penelitian menunjukkan bahwa terdapat hubungan yang signifikan antara dosen pembimbing, teman sebaya dan lingkungan dengan ansietas mahasiswa yang sedang menyelesaikan tugas akhir

\section{SARAN}

Penelitian ini bisa digunakan sebagai bahan referensi untuk penelitian selanjutnya dengan tema bagaimana cara untuk mengurangi 
Eka Malfasari ${ }^{1}$, Yeni Devita ${ }^{2}$, Fitry Erlin $^{3}$, Filer $^{4}$,Faktor-Faktor Yang Mempengaruhi Kecemasan Mahasiswa Dalam Menyelesaikan Tugas Akhir Di Stikes Payung Negeri Pekanbaru

kecemasan pada mahasiswa yang sedang menghadapi tugas akhir.

\section{DAFTAR PUSTAKA}

Alafgani, A. P. (2013) Analisis FaktorFaktor Kesulitan Mahasiswa Jurusan Pendidikan Teknik Arsitektur Fptk Upi Dalam Penyelesaian Tugas akhir di askes dari repository.upi.edu/2435

Batara, P. (2010). Solusi Cerdas Mengatasi Cemas. Jakarta: ST Book

Demak, I.P.K, Suherman. (2016). Hubungan Umur, Jenis Kelamin Mahasiswa Dan Pendapatan Orangtua Dengan Tingkat Kecemasan Pada Mahasiswa Pendidikan Sarjana Program Studi Pendidikan Dokter FKIK Universitas Tadulako jurnal.untad.ac.id/ diakses pada 14 Januari 2017

Hartato, (2016). Faktor-Faktor Yang Mempengaruhi Penyelesaian Tugas Akhir Tugas akhir Mahasiswa Program Studi Pendidikan Akuntansi Fakultas Ekonomi Universitas Negeri Yogyakarta Angkatan 2011 Diperoleh tanggal 08 Januari 2017 dari eprints.uny.ac.id/30748/1/Ujang $\% 20 H a r t a t o \% 20 \_\% 2012803249001 . p d f$

Hawari, D. (2011). Manajemen Stress, Cemas, Dan Depresi. Jakarta : FKUI

Irham, M \& Wiyani, N. A (2013). Psikologi Pendidikan. Jogjakarta: Ar-ruzz Media Irmayanti, \& Warsito. (2012). Penerapan Strategi Relaksasi Untuk Mengurangi Kecemasan Mahasiswa Menjelang Ujian VOL. 6. Surabaya : FIP Unesa

Kaplan, \& sadock. (2010). Buku Ajar Psikiatri Klinis (Concise Textbook Of Clinical Psychiatry). Jakarta : EGC

Kusnendar, F \& Suwachid \& Wijayanto, D. S (2013) Analisis Penghambat Penyelesaian Studi Mahasiswa S1 Program Studi Pendidikan Teknik Mesin Jurusan Pendidikan Teknik Dan Kejuruan Fakultas Keguruan Dan Ilmu Pendidikan Universitas Sebelas Maret Surakarta diakses dari www.journal.unair.ac.id/downloadfullpapers-jppp 8 c3437b5d82fu
Mukhayyaroh, L. (2012). Kecemasan Menyusun Tugas Akhir Ditinjau Dari Berpikir Positif pada mahasiswa Program Studi DIII Kebidanan Universitas Muhammadiyah Semarang http://ilib.usm.ac.id/ diakses pada $28 \mathrm{Feb}$ 2017

Prabowo, (2010). Gambaran gangguan kecemasan pada mahasiswa fakultas kedokteran universita "x" angkatan 2007. Di peroleh tanggal 16 Februari 2017 dari majour.maranatha.edu/

Purwanto, M.N. (2007). Psikologi Pendidikan. Bandung : CV. Pustaka Setia

Riyadi, \& Purwanto, T. (2009). Asuhan Keperawatan Jiwa. Yogyakarta: Graha Ilmu 